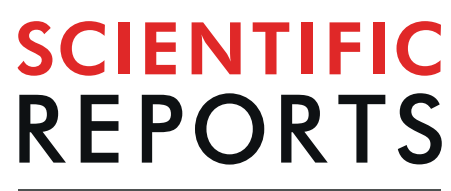

natureresearch

\title{
OPEN Probing conformational changes of monomeric transthyretin with second derivative fluorescence
}

Received: 30 November 2018

Accepted: 2 July 2019

Published online: 29 July 2019

\begin{abstract}
Denisa Jazaj, Seyyed Abolghasem Ghadami, Francesco Bemporad (iD \& Fabrizio Chiti $(\mathbb{D}$
We have studied the intrinsic fluorescence spectra of a monomeric variant of human transthyretin (M-TTR), a protein involved in the transport of the thyroid hormone and retinol and associated with various forms of amyloidosis, extending our analysis to the second order derivative of the spectra. This procedure allowed to identify three peaks readily assigned to Trp41, as the three peaks were also visible in a mutant lacking the other tryptophan (Trp79) and had similar FRET efficiency values with an acceptor molecule positioned at position 10 . The wavelength values of the three peaks and their susceptibility to acrylamide quenching revealed that the three corresponding conformers experience different solvent-exposure, polarity of the environment and flexibility. We could monitor the three peaks individually in urea-unfolding and $\mathrm{pH}$-unfolding curves. This revealed changes in the distribution of the corresponding conformers, indicating conformational changes and alterations of the dynamics of the microenvironment that surrounds the associated tryptophan residue in such transitions, but also native-like conformers of such residues in unfolded states. We also found that the amyloidogenic state adopted by $\mathrm{M}$-TTR at mildly low $\mathrm{pH}$ has a structural and dynamical microenvironment surrounding Trp41 indistinguishable from that of the fully folded and soluble state at neutral $\mathrm{pH}$.
\end{abstract}

Human transthyretin (TTR) is a protein consisting of a tetramer of four identical subunits ${ }^{1,2}$. It is predominantly synthesized by liver hepatocytes, epithelial cells of the brain choroid plexus, and the retinal pigment epithelium, but also in many other tissues to a lower extent ${ }^{1,2}$. In the plasma, TTR is a secondary transporter of the thyroid hormone and a primary transporter of the retinol binding protein (RBP), whereas in the cerebrospinal fluid (CSF) it is the main transporter of the thyroid hormone $\mathrm{e}^{1,3,4}$.

The misfolding and aggregation of TTR to form different types of fibrillar aggregates, known as amyloid fibrils, is associated with several human pathologies, collectively referred to as $\mathrm{ATTR}^{5,6}$. In these diseases, the aggregates have a well-defined fibrillar appearance, a cross- $\beta$ structure and characteristic tinctorial properties following the staining with amyloid-diagnostic dyes $s^{7,8}$. Deposition of amyloid by wild-type TTR in the heart occurs for $10-25 \%$ of humans older than 80 , resulting in a pathological condition known as senile systemic amyloidosis $(\mathrm{SSA})^{9,10}$. Amyloid formation by any of the ca. 100 different variants of TTR so far described leads to early-onset TTR amyloidosis with autosomal dominant inheritance, such as familial amyloid cardiomyopathy (FAC), familial amyloid polyneuropathy (FAP), and leptomeningeal amyloidosis ${ }^{11,12}$. Hence, the predominant species within amyloid fibrils in TTR-related familial conditions is mutant $\mathrm{TTR}^{7,13-15}$. The single mutations that give rise to such conditions do not significantly perturb the structure of tetrameric TTR, but rather reduce the kinetic and/ or thermodynamic stability of native TTR in its tetrameric form, so that the population of the partially unfolded amyloidogenic intermediate in the monomeric form is increased ${ }^{5,16,17}$.

The TTR community has expended considerable effort to investigate the structure and dynamics of potentially relevant forms of TTR, including wild-type tetrameric $\mathrm{TTR}^{18-22}$, a monomeric conformational state populated at low $\mathrm{pH}$ or following a specific double mutation ${ }^{19,20,23-26}$ and amyloid fibrils ${ }^{27,28}$. Such efforts have been made not just under physiological conditions, but also under a number of experimental conditions known to promote amyloid fibril formation by stabilising partially folded monomeric states, possibly acting as amyloidogenic precursor states; these include mildly acidic $\mathrm{pH}$ values ${ }^{19,20,24,26}$, high values of hydrostatic pressure ${ }^{29}$, small concentrations of urea ${ }^{26,30}$ or native conditions after a jump of urea concentration to detect partially folded states accumulating during folding ${ }^{26,30}$.

Dipartimento di Scienze Biomediche Sperimentali e Cliniche "Mario Serio", Sezione di Scienze Biochimiche, Università degli Studi di Firenze, Viale Morgagni 50, 50134, Firenze, Italy. Correspondence and requests for materials should be addressed to F.C. (email: fabrizio.chiti@unifi.it) 
The intrinsic fluorescence of tryptophan residues contained in proteins has been widely used to determine and monitor the structural changes occurring during protein conformational conversions. Advantages of this technique over other methods include its high sensitivity, the small protein contents and concentrations required to obtain high quality fluorescence spectra, the high signal-to-noise ratio, the rapidity of data acquisition, the sensitivity of the wavelength of maximum fluorescence $\left(\lambda_{\max }\right)$ and quantum yield to even subtle structural changes ${ }^{31-34}$. Nevertheless, intrinsic tryptophan fluorescence has many additional potentialities that have not been fully exploited to monitor protein conformational changes. One of these is the analysis of the second derivative of fluorescence spectra to identify contributions of different tryptophan residues, or even different conformations of individual tryptophan residues, to the overall fluorescence spectra ${ }^{35,36}$. Such an approach has been used to study a few proteins in the past ${ }^{35-39}$, but has never been applied to study any TTR form in any of its conformational states, and has not reached any substantial level of detail even in other protein systems.

Monomeric TTR has two tryptophan residues, numbered 41 and 79 . Trp41 has a very important location, because it is in $\beta$-strand $\mathrm{C}$ that has been described to be either fully folded or unfolded in the amyloidogenic state populated at acidic $\mathrm{pH}$ in the different structural studies reported so $\mathrm{far}^{19-22,24,26}$. In this manuscript we have thus analysed the gross fluorescence spectra and their second derivative of the F87M/L110M mutant of TTR that has been designed to be stable as a monomer $(\mathrm{M}-\mathrm{TTR})^{23}$, and of another mutant carrying the additional single-point W79F substitution, thus containing the single tryptophan at position 41 . We have carried out this analysis under a variety of conditions where fully folded, fully unfolded or partially folded (and potentially amyloidogenic states) are populated. We will show that it is possible to monitor various conformations of individual tryptophan residues during the various structural transitions involving the whole protein, which allows determining not just changes on the chemical environment around the tryptophan residues, but also modifications of their dynamics as the overall structural transitions occur and native-like conformers of such residues.

\section{Results}

M-TTR and its W79F mutant have complex intrinsic fluorescence spectra. We initially recorded the intrinsic fluorescence spectra (290 nm excitation) of M-TTR and W79F M-TTR in $20 \mathrm{mM}$ phosphate buffer, $\mathrm{pH} 7.4,25^{\circ} \mathrm{C}$ at a protein concentration of $3 \mu \mathrm{M}$ (Fig. 1A). The two spectra were found to be superimposable and very similar in terms of fluorescence intensity, indicating that only Trp41 contributes to the overall intrinsic fluorescence of folded M-TTR and that the fluorescence of Trp79 is quenched in this conformation. This was previously observed for tetrameric WT-TTR ${ }^{19}$ and confirmed for M-TTR under our conditions of analysis (Fig. 1A).

In mathematical terms, a fluorescence emission spectrum represents the fluorescence emission intensity $(\mathrm{F}$, arbitrary units) at various values of wavelength ( $\lambda$, units of $\mathrm{nm})$, at a given excitation wavelength, and the two spectra reported in Fig. 1A follow this well-established convention. We calculated their second derivative, which consists of the second order derivative of $F$ with respect to $\lambda\left(d^{2} F / d \lambda^{2}\right)$ and plotted them in Fig. 1C. The second derivative spectra of M-TTR and W79F M-TTR reveal three peaks at $c a$. $322-325 \mathrm{~nm}, 342-348 \mathrm{~nm}$ and $362-369 \mathrm{~nm}$ and a shoulder at ca. $304 \mathrm{~nm}$ (Fig. 1C). The $304 \mathrm{~nm}$ peak can be assigned to one or more of the five tyrosine residues of M-TTR, as $304 \mathrm{~nm}$ is just the wavelength of maximum fluorescence for tyrosine side chains ${ }^{34}$. The three remaining peaks are located in a wavelength range typical of tryptophan residues ${ }^{34,40}$, but the question arises as to how a single residue, such as Trp41, can give rise to three peaks with such distinct wavelengths.

The fluorescence emission spectra of free L-tryptophan and N-Acetyl-L-tryptophanamide (NATA), as well as their second derivative spectra, are characterised by one major peak at ca. 355-360 nm (Fig. 1B,D), as expected for these compounds ${ }^{34,40}$. The presence of three peaks in the fluorescence spectra of M-TTR and its W79F mutant, in the wavelength window of $320-370 \mathrm{~nm}$, is therefore a peculiarity of this protein and its mutant.

The three peaks at 320-370 $\mathrm{nm}$ in the second derivative spectra arise from Trp41. In order to investigate the origin of the three peaks in the second derivative fluorescence spectra of M-TTR and its W79F mutant in the wavelength region of $320-370 \mathrm{~nm}$, we acquired the fluorescence spectra ( $290 \mathrm{~nm}$ excitation) of the two protein variants labelled with $\mathrm{N}$-(7-dimethylamino-4-methylcoumarin-3-yl)maleimide (DACM), at Cys10 (DACM-M-TTR and W79F DACM-M-TTR) with various degrees of labelling ranging from $0 \%$ to $100 \%$ (Fig. 2A,B). DACM is a coumarin derivative acting as an acceptor of the Trp41 fluorescence in fluorescence resonance energy transfer (FRET), which therefore acts as a FRET donor ${ }^{26}$. All spectra were again acquired in $20 \mathrm{mM}$ phosphate buffer, $\mathrm{pH} 7.4,25^{\circ} \mathrm{C}$ at a protein concentration of $3 \mu \mathrm{M}$. As observed previously ${ }^{26}$, for both protein variants the tryptophan fluorescence emission at 320-370 $\mathrm{nm}$ decreases with the increase of DACM labelling, indicating the presence of effective FRET (Fig. 2A,B). Concomitantly, the DACM fluorescence emission at $463 \mathrm{~nm}$ increases with the increase of DACM labelling, again indicating the occurrence of FRET (Fig. 2A,B).

We then calculated second derivatives of these spectra (Fig. 2C,D). The tyrosine peak at $304 \mathrm{~nm}$ and the three peaks at 320-370 $\mathrm{nm}$ are present in all cases. The three peaks at $320-370 \mathrm{~nm}$, unlike the peak at $304 \mathrm{~nm}$, decrease in intensity with DACM labelling in both protein variants (Fig. 1C-F), suggesting that they all arise from Trp41 fluorescence that is effectively transferred to DACM through FRET. The peak at $304 \mathrm{~nm}$ does not decrease and indeed increases apparently in intensity, most probably because the decrease of the other three peaks unravel it more markedly. The three peaks at 320-370 nm decrease to similar extents with DACM labelling (Fig. 1E,F). The peak at $325 \mathrm{~nm}$ of M-TTR is the only one that decreases less markedly relative to the other two (Fig. 1E), but this behaviour was not found for the corresponding peak in the W79F mutant (Fig. 1F), implying that the apparent change is not significant. The finding that the second derivative values of the three peaks decrease to similar extents in the presence of DACM-labelling indicates that they all arise from donors located spatially at very similar distances from the DACM acceptor, as the FRET efficiency is highly dependent on the donor-acceptor distance $e^{26,34,41}$. These observations indicate that the three peaks that are apparent in the $320-370 \mathrm{~nm}$ region of the second derivative spectra all arise from Trp41, possibly from three different conformers (rotamers) of this residue. 

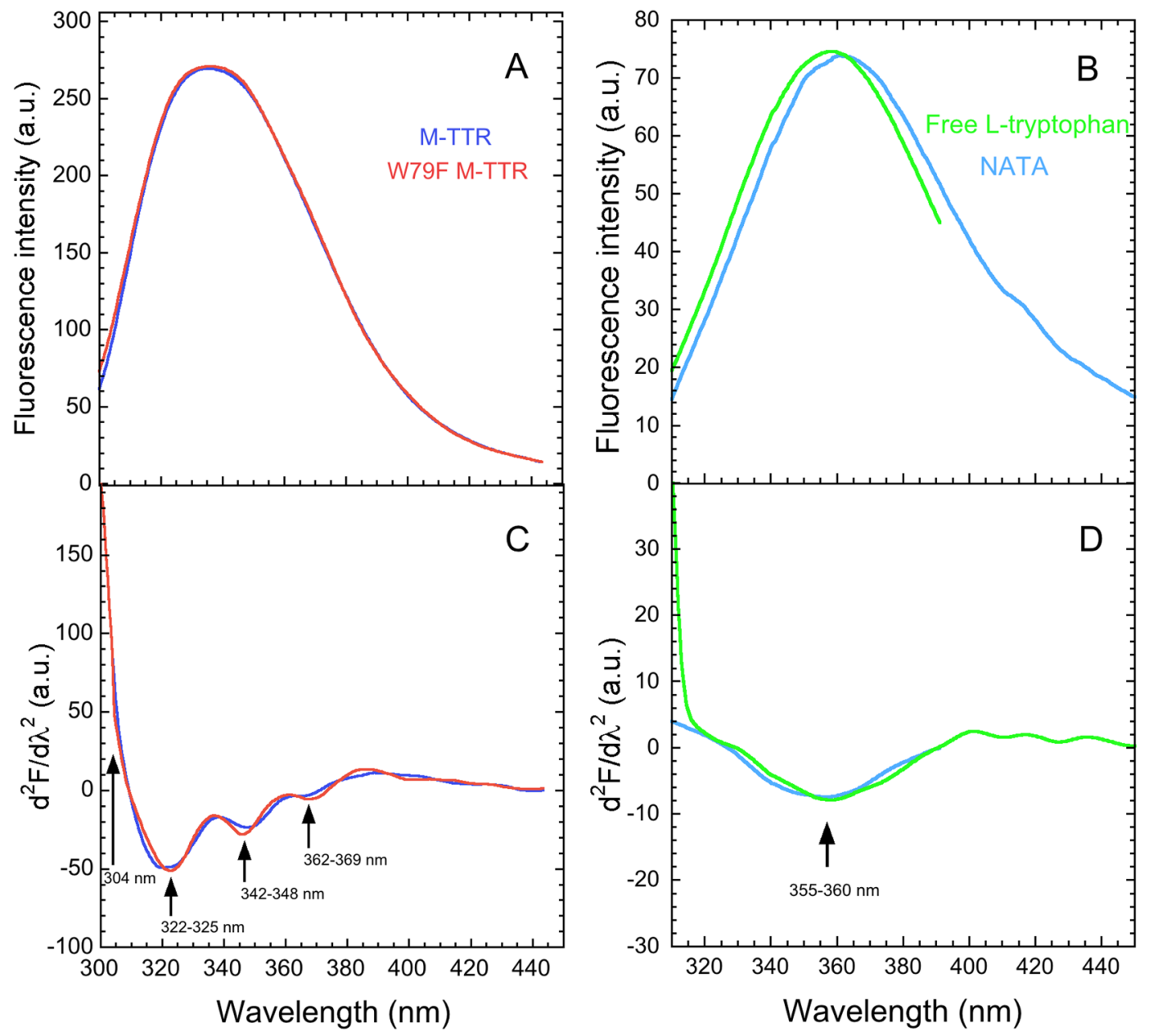

Figure 1. Gross and second derivative fluorescence spectra of M-TTR, W79F M-TTR, free L-tryptophan and NATA. (A,B) Fluorescence emission spectra (excitation $290 \mathrm{~nm}$, slits 5 and $10 \mathrm{~nm}$ for ex and em, respectively) of M-TTR and its W79F mutant (A) and of free L-tryptophan and NATA (B) at a concentration of $3 \mu \mathrm{M}$, in $20 \mathrm{mM}$ phosphate buffer, $\mathrm{pH} 7.4,25^{\circ} \mathrm{C}$. (C,D) Calculated second derivative spectra of M-TTR and W79F M-TTR (C) and of free L-tryptophan and NATA (D).

The different wavelengths of emitted fluorescence of the three Trp41 conformers suggest that they have different degrees of hydrophobic contacts, hydrogen bonding and solvent exposure in the native protein.

The three peaks at 320-370 nm undergo different quenching by acrylamide. In order to investigate further the solvent-exposure of the three Trp41 conformers that give rise to the different peaks, we recorded the fluorescence emission spectra $(290 \mathrm{~nm}$ excitation) of M-TTR and its W79F mutant in $20 \mathrm{mM}$ phosphate buffer, $\mathrm{pH} 7.4,25^{\circ} \mathrm{C}$, using progressive additions of acrylamide as a quencher of tryptophan fluorescence (Figs $3 \mathrm{~A}$ and $4 \mathrm{~A}$ ). For these spectra, larger slit widths of emission were used to increase the fluorescence intensity at high acrylamide concentrations, where acrylamide is expected to quench the signal. The subsequent spillover of signal at low wavelength values $(<306 \mathrm{~nm})$ is indeed due to the excitation light that reached the detector by diffusion at these wavelength values. As expected, the increase of acrylamide concentration decreases the intrinsic protein fluorescence as the fluorescence of Trp41 is progressively quenched upon addition of acrylamide regardless of its adopted conformer and solvent exposure ${ }^{42}$. We plotted the ratio of total fluorescence intensity in the absence $\left(F_{0}\right)$ and presence $(F)$ of acrylamide $\left(F_{0} / F\right)$ versus acrylamide concentration to determine the Stern-Volmer constant $\left(K_{S V}\right)$ value (see Materials and methods for details). These values were found to be $5.60 \pm 0.13 \mathrm{M}^{-1}$ for M-TTR and $5.58 \pm 0.04 \mathrm{M}^{-1}$ for the W79F mutant (Figs $3 \mathrm{~B}$ and $4 \mathrm{~B}$ ). This reveals similar quenching degrees of the Trp41 residue for both variants.

We then converted all the spectra into their second derivative (Figs $3 \mathrm{C}$ and $4 \mathrm{C}$ ) and produced plots of $F_{0} / F$ versus acrylamide concentration for the three identified second derivative negative peaks (Figs $3 \mathrm{D}$ and $4 \mathrm{D}$ ). All three peaks decrease in intensity with the increase of acrylamide concentration, confirming that they arise from a tryptophan residue, i.e. Trp41. The two peaks at 343 and $362 \mathrm{~nm}$ decrease in intensity to similar degrees with acrylamide quenching and more effectively than the peak at $323 \mathrm{~nm}$, suggesting that they arise from conformers that are more exposed to the solvent. The $K_{S V}$ values for the three second derivative peaks of M-TTR were found to be $6.26 \pm 0.28 \mathrm{M}^{-1}$ at $323 \mathrm{~nm}, 12.01 \pm 0.79 \mathrm{M}^{-1}$ at $343 \mathrm{~nm}$ and $10.33 \pm 0.97 \mathrm{M}^{-1}$ at $362 \mathrm{~nm}$. The analysis for the W79F mutant was not entirely successful as the high signal-to-noise ratio prevented from acquiring good 

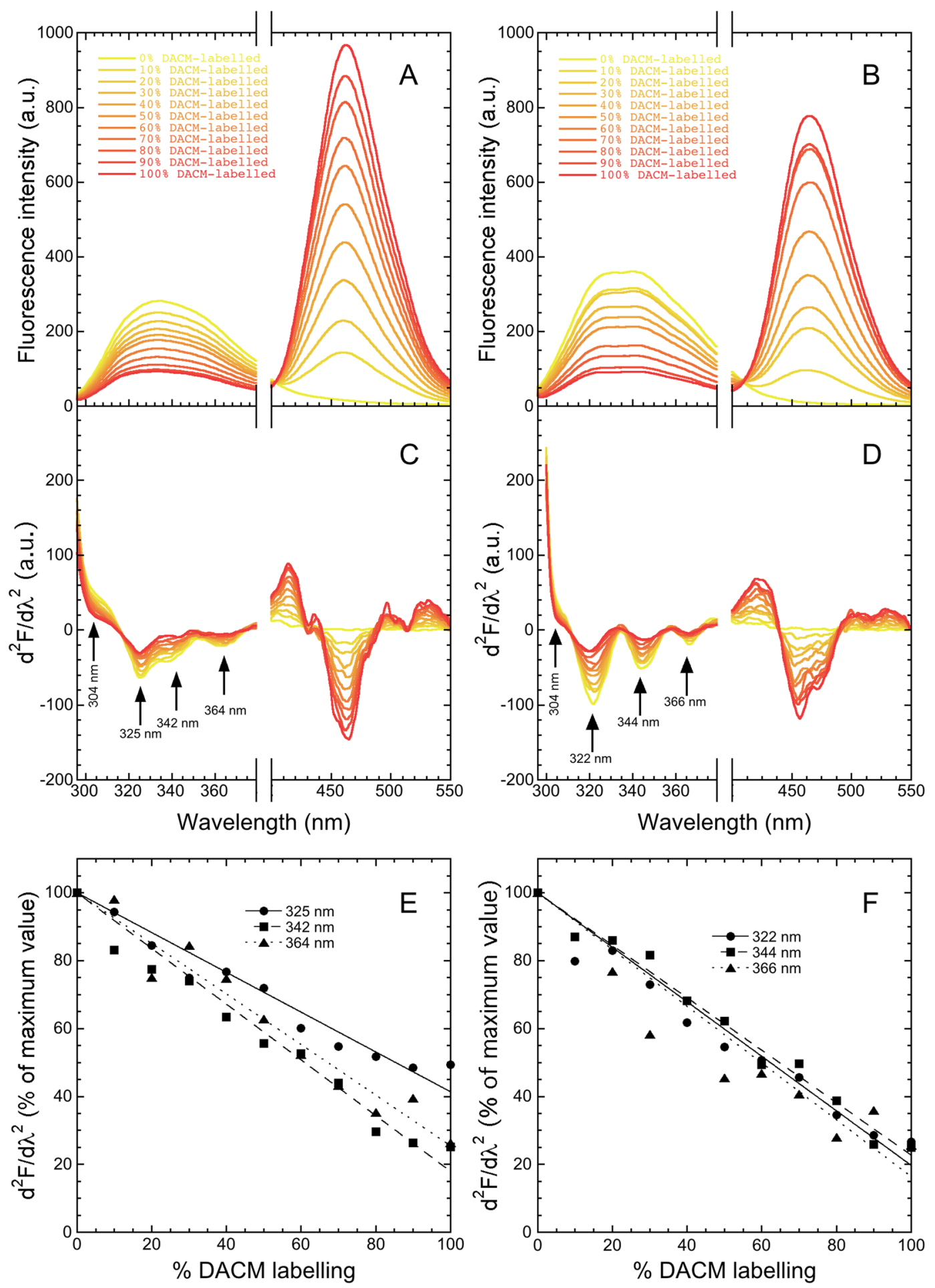

Figure 2. Gross and second derivative fluorescence spectra of M-TTR and W79F M-TTR with various degrees of DACM-labelling. (A,B) Fluorescence spectra (excitation $290 \mathrm{~nm}$, slits 2.5 and $5 \mathrm{~nm}$ for ex and em, respectively) of mixtures of M-TTR and DACM-M-TTR (A) or W79F M-TTR and W79F DACM-M-TTR (B) at the indicated percentages of the DACM-labelled protein, at $3 \mu \mathrm{M}$ total protein concentration, in $20 \mathrm{mM}$ phosphate buffer, $\mathrm{pH} 7.4,25^{\circ} \mathrm{C}$. (C,D) Corresponding second derivative spectra for M-TTR $(\mathbf{C})$ and W79F M-TTR (D) with arrows indicating the major peaks arising from tyrosine residues ( $304 \mathrm{~nm})$ and tryptophan residues $(320-370 \mathrm{~nm})$. (E,F) Values of second derivative as a function of DACM-labelling percentage for the three indicated peaks of M-TTR (E) and W79F M-TTR. (F) To facilitate the comparison, all values were normalised attributing $100 \%$ to those determined with $0 \%$ labelling. The lines through the data represent the best fits to a linear function of the form $\mathrm{d}^{2} \mathrm{~F} / \mathrm{d} \lambda^{2}=100 \%+a \cdot(\%$ DACM labelling). 
M-TTR

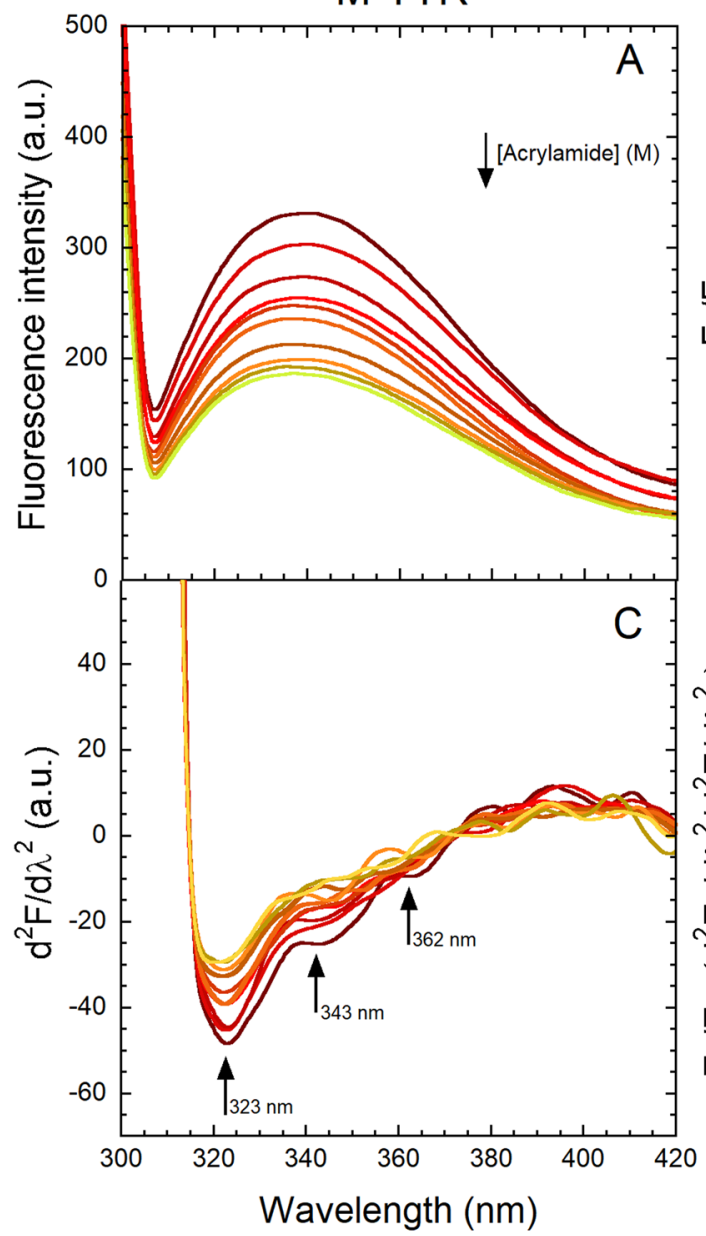

M-TTR

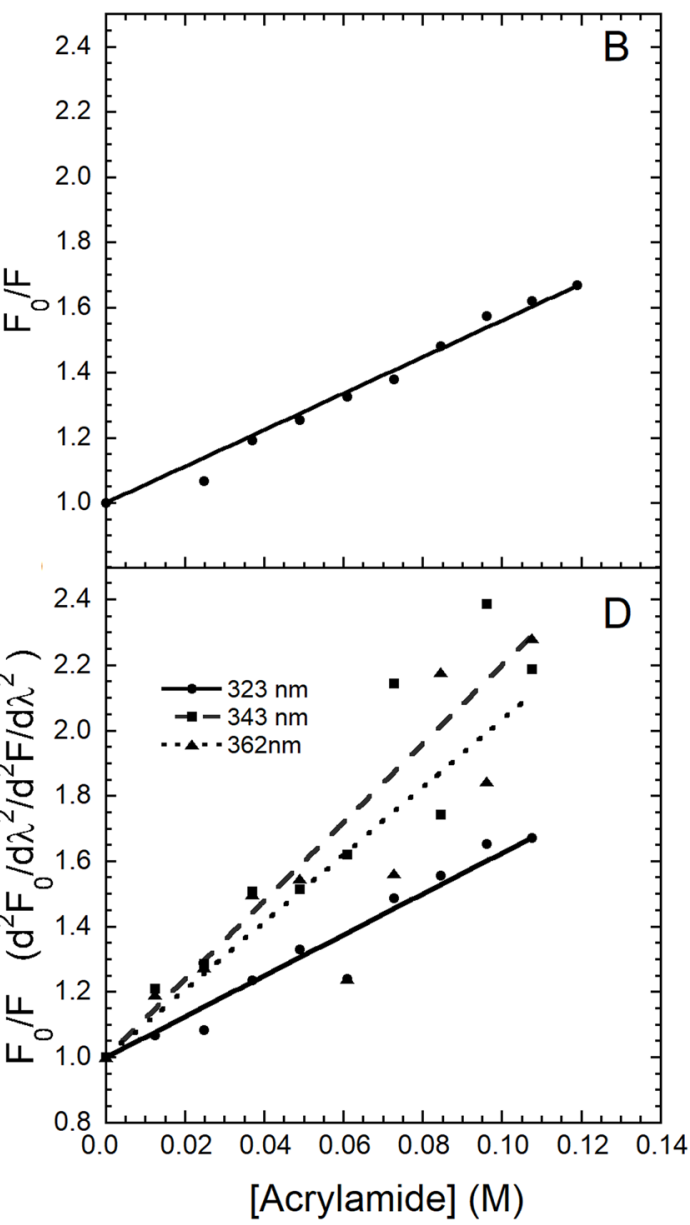

Figure 3. Quenching of M-TTR fluorescence spectra by acrylamide. (A) Fluorescence spectra (excitation $290 \mathrm{~nm}$, slits 2.5 and $18 \mathrm{~nm}$ for ex and em, respectively) of $2.2 \mu \mathrm{M} \mathrm{M}$-TTR following progressive additions of small volumes of $2.5 \mathrm{M}$ acrylamide in $20 \mathrm{mM}$ phosphate buffer, $\mathrm{pH} 7.4,25^{\circ} \mathrm{C}$. (B) Plot of the ratio of total fluorescence intensity in the absence $\left(F_{0}\right)$ and presence $(F)$ of acrylamide $\left(F_{0} / F\right)$ versus acrylamide concentration. The straight line represents the best fit of the data points to the Stern-Volmer linear function (Eq. 1) to determine the $K_{\mathrm{SV}}$ value. (C) Corresponding second derivative spectra with arrows indicating the major peaks at 323,343 and $362 \mathrm{~nm}$. (D) $F_{0} / F$ versus acrylamide concentration for the three indicated second derivative peaks, where $F_{0}$ and $F$ values are second derivative values. The lines through the data represents the best fit to the Stern-Volmer linear function (Eq. 1).

second derivative spectra at the two higher wavelengths with consequently noisy Stern-Volmer plots. We could determine only a $K_{S V}$ value for the $323 \mathrm{~nm}$ peak, which was found to be $6.57 \pm 0.17 \mathrm{M}^{-1}$, in agreement with that determined for the non-mutated M-TTR. Overall, we noticed a low $K_{S V}$ value at $323 \mathrm{~nm}$ in both variants and this indicates a lower solvent-exposure of the corresponding Trp41 conformation relative to the other conformers.

The second derivative spectra change with urea titration. We then acquired the fluorescence spectra ( $290 \mathrm{~nm}$ excitation) of M-TTR at various urea concentrations ranging from 0 to $7.2 \mathrm{M}$, again in $20 \mathrm{mM}$ phosphate buffer, $\mathrm{pH} 7.4,25^{\circ} \mathrm{C}$ (Fig. 5A) and converted them into their second derivative (Fig. 5B). The gross spectra undergo a red shift of its wavelength of maximum fluorescence emission $\left(\lambda_{\max }\right)$ and an increase of fluorescence emission intensity as the urea concentration increases (Fig. 5A). The first phenomenon occurs because Trp41 becomes more exposed to the solvent upon unfolding ${ }^{32,34}$, whereas the increase in fluorescence intensity is a probable consequence of the removal of Trp79 quenching as the protein unfolds ${ }^{19,26}$.

The plot of fluorescence intensity at the representative wavelength of $362 \mathrm{~nm}$ against urea concentration, i.e. the equilibrium urea denaturation curve, reveals a single cooperative transition between ca. 2.0 and $3.6 \mathrm{M}$ urea and pre- and post-transition values that increase gradually and linearly with urea concentration, as a result of the lower quenching of tryptophan fluorescence by urea relative to water (Fig. 5B). The urea denaturation curve was analysed with a two-state unfolding model using a well-established procedure ${ }^{43,44}$, which provided quantitative measurements of the free energy change upon unfolding in the absence of denaturant $\left(\Delta G_{U-F}^{H 20}\right)$, its dependence on urea concentration ( $m$ value) and the concentration of $50 \%$ denaturation $\left(C_{m}\right)$. These values were found to be 

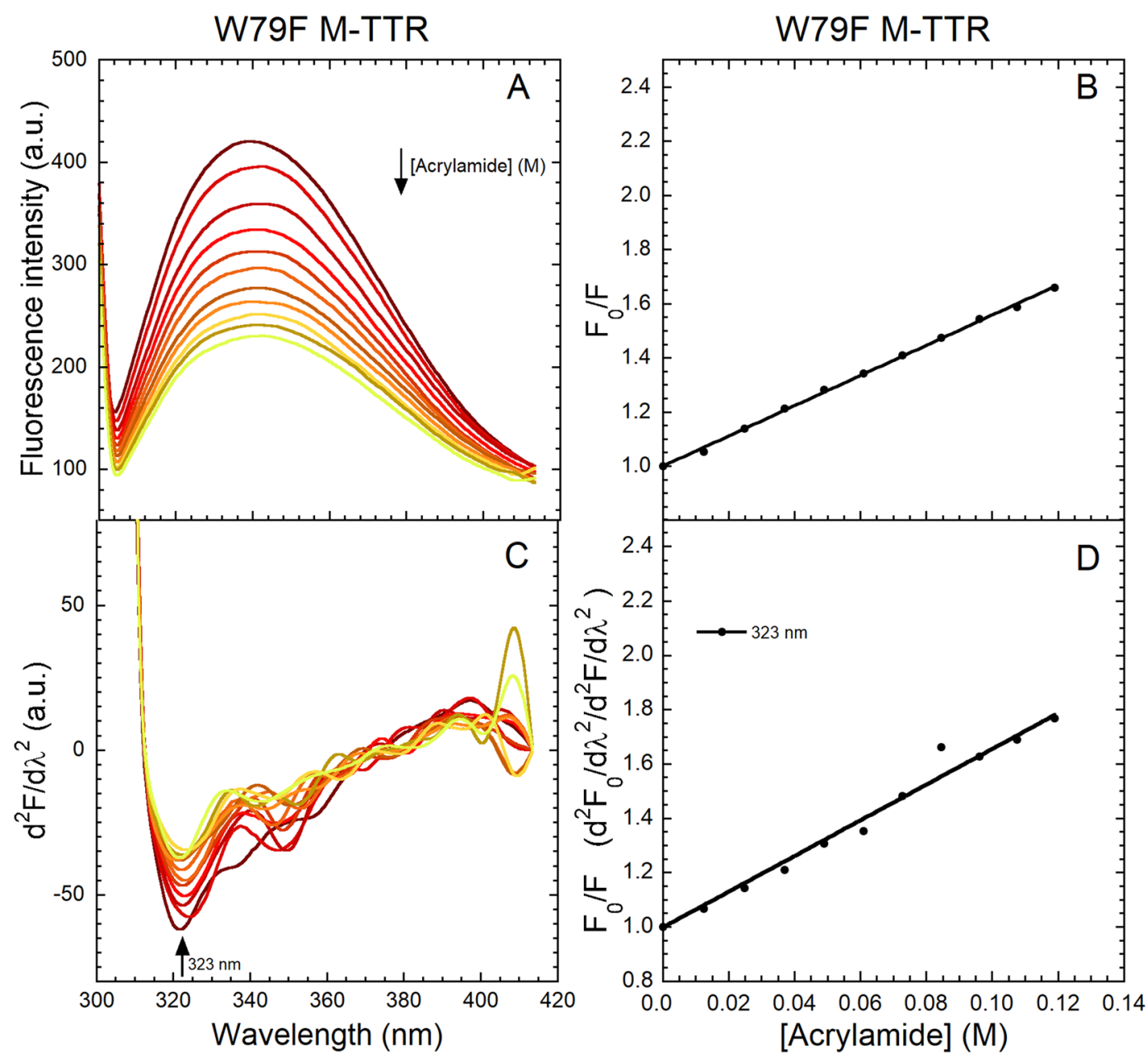

Figure 4. Quenching of W79F M-TTR fluorescence spectra by acrylamide. (A) Fluorescence spectra (excitation $290 \mathrm{~nm}$, slits 2.5 and $14 \mathrm{~nm}$ for ex and em, respectively) of $3.5 \mu \mathrm{M}$ W79F M-TTR following progressive additions of $2.5 \mathrm{M}$ acrylamide in $20 \mathrm{mM}$ phosphate buffer, $\mathrm{pH} 7.4,25^{\circ} \mathrm{C}$. (B) Plot of the ratio of total fluorescence intensity in the absence $\left(F_{0}\right)$ and presence $(F)$ of acrylamide $\left(F_{0} / F\right)$ versus acrylamide concentration. The straight line represents the best fit of the data points to the Stern-Volmer linear function (Eq. 1) to determine the $K_{\mathrm{SV}}$ value. (C) Corresponding second derivative spectra with the indicated major peak at $323 \mathrm{~nm}$. (D) $F_{0} / F$ versus acrylamide concentration for the indicated second derivative peak, where $F_{0}$ and $F$ values are second derivative values. The lines through the data represents the best fit to the Stern-Volmer linear function (Eq. 1).

$20.7 \pm 3.5 \mathrm{~kJ} \mathrm{~mol}^{-1}, 7.8 \pm 1.3 \mathrm{~kJ} \mathrm{~mol}^{-1} \mathrm{M}^{-1}$ and $2.8 \pm 0.2 \mathrm{M}$, respectively, in agreement with those previously reported of $20.4 \pm 1.5 \mathrm{~kJ} \mathrm{~mol}^{-1}, 6.9 \pm 0.5 \mathrm{~kJ} \mathrm{~mol}^{-1} \mathrm{M}^{-1}$ and $3.0 \pm 0.1 \mathrm{M}^{26}$.

In the second derivative spectra three peaks were again apparent in the region of light of $320-370 \mathrm{~nm}$ (Fig. 5C). The second derivative values at $325 \mathrm{~nm}, 348 \mathrm{~nm}$ and $364 \mathrm{~nm}$ were plotted versus urea concentration to obtain urea denaturation curves using the second derivative values rather than the gross fluorescence intensity values, as generally done (Fig. 5D). A first interesting observation is that the first peak at $325 \mathrm{~nm}$ decreases in intensity (becomes less negative) with urea concentration, whereas the second and third peaks at 348 and $364 \mathrm{~nm}$ increase (Fig. 5D). This indicates that the distribution of the three conformers of Trp41 observed in the absence of urea changes upon unfolding at high urea concentration. In particular, the population of the first conformer decreases and those of the other two increase upon unfolding (Fig. 5D). Such changes are cooperative, however, and occur within the same range of urea concentration. Indeed, the $\left(\Delta G_{U-F}^{H 20}\right), m$ and $C_{m}$ values determined from such curves are similar, within experimental error, to each other and to those obtained here and previously ${ }^{26}$ from the fluorescence intensity values (Table 1 ).

The analysis was repeated for the W79F mutant of M-TTR (Fig. 6). In this case the gross spectra have a red shift of the $\lambda_{\max }$ value, as observed for M-TTR, but no increase of fluorescence emission as the urea concentration increases, most probably because Trp79 is absent altogether and does not contribute to the overall fluorescence in the unfolded protein (Fig. 6A). The equilibrium urea denaturation curve at $330 \mathrm{~nm}$ reveals a single cooperative transition with $\Delta G_{U-F}^{H 20}, m$ and $C_{m}$ values of $12.9 \pm 1.3 \mathrm{~kJ} \mathrm{~mol}^{-1}, 4.2 \pm 0.4 \mathrm{~kJ} \mathrm{~mol}^{-1} \mathrm{M}^{-1}$ and $3.1 \pm 0.2 \mathrm{M}$, respectively (Fig. 6B and Table 1), in agreement with those previously reported of $13.0 \pm 1.4 \mathrm{~kJ} \mathrm{~mol}^{-1}, 4.3 \pm 0.4 \mathrm{~kJ} \mathrm{~mol}^{-1} \mathrm{M}^{-1}$ 

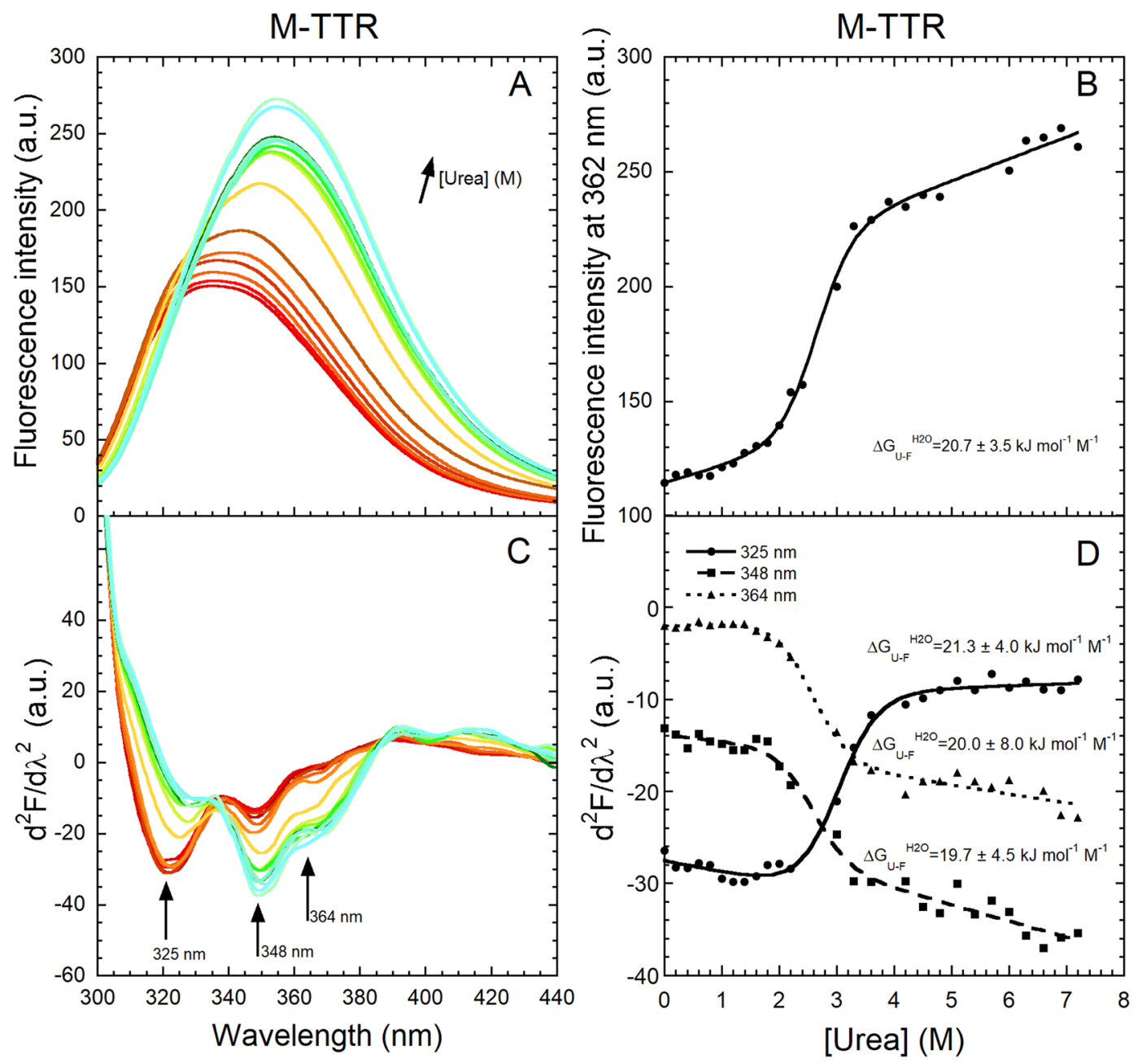

Figure 5. Equilibrium urea unfolding of M-TTR. (A) Fluorescence spectra (excitation $290 \mathrm{~nm}$, slits 5 and $10 \mathrm{~nm}$ for ex and em, respectively) at $60 \mu \mathrm{M}$ protein concentration and urea concentrations ranging from 0 to $7.2 \mathrm{M}$ in $20 \mathrm{mM}$ phosphate buffer, at $\mathrm{pH} 7.4,25^{\circ} \mathrm{C}$. (B) Urea denaturation curve using fluorescence intensity at $362 \mathrm{~nm}$. The solid line through the data represents the best fit to a two-state model (Santoro and Bolen, 1988). The obtained $\Delta G_{U-F}^{H 20}$ value is shown. (C) Corresponding second derivative spectra with arrows indicating the major peaks. (D) Values of second derivative at 325, 348 and $364 \mathrm{~nm}$ versus urea concentration, plotted to obtain urea denaturation curves. The solid lines through the data represent the best fit to a two-state model (Santoro and Bolen, 1988). The obtained $\Delta G_{U-F}^{H 20}$ values are shown.

and $3.0 \pm 0.1 \mathrm{M}^{26}$. In the second derivative spectra the three peaks associated with Trp41 at 320-370 nm are well defined (Fig. 6C). The first peak at $324 \mathrm{~nm}$ decreases and the third peak at $367 \mathrm{~nm}$ increases with urea concentration, whereas the second peak at $346 \mathrm{~nm}$ remains apparently stable (Fig. 5D). This indicates that the population of the first conformer of Trp41 decreases and that of the third conformer increases upon unfolding (Fig. 6D). Such changes are again cooperative, however, with $\Delta G_{U-F}^{H 20}, m$ and $C_{m}$ values similar, within experimental error, to each other and to those obtained from the gross fluorescence intensity values at $330 \mathrm{~nm}$ (Table 1). We should note, however, that the $367 \mathrm{~nm}$ transition is very subtle and the thermodynamic parameters have inevitably high experimental errors and that a transition with the $346 \mathrm{~nm}$ peak was not apparent altogether (Table 1 ).

The second derivative spectra change with $\mathrm{pH}$ titration, but only at $\mathrm{pH}$ extremes. We also extended our analysis at various $\mathrm{pH}$ values ranging from 10.0 to 1.5 to detect possible changes involving the Trp41 as the $\mathrm{pH}$ decreases from weakly alkaline to neutral values and then from neutral to acidic values. This investigated range of $\mathrm{pH}$ includes the window of $\mathrm{pH} 3.9-5.0$, in which the amyloidogenic state of the protein is populated ${ }^{19,20,24,26}$. We therefore acquired the fluorescence spectra of M-TTR (excitation $280 \mathrm{~nm}$ ) in 36 different buffers having different $\mathrm{pH}$ values, all having a constant ionic strength of $30 \mathrm{mM}$, a temperature of $25^{\circ} \mathrm{C}$ and a protein concentration of $3 \mu \mathrm{M}$. The underivatized fluorescence emission intensity appears to increase linearly as the $\mathrm{pH}$ decreases from 10.0 to 3.4, with the spectra maintaining a similar overall shape (Fig. 7A). This is confirmed by the $\mathrm{pH}$ titration of the fluorescence intensity at a representative wavelength of $335 \mathrm{nM}$ (Fig. 7B). Such a weak and linear behaviour is a typical solvent effect and rules out a significant change of the chemical environment of Trp41 within this range of $\mathrm{pH}$ values. The overall fluorescence emission then decreases, and a marked spectral shape 


\begin{tabular}{|c|c|c|c|c|c|}
\hline Parameter & $\begin{array}{l}\text { Gross fluorescence } \\
\text { at } 362 \mathrm{~nm}\end{array}$ & $\begin{array}{l}\mathrm{d}^{2} \mathrm{~F} / \mathrm{dx}^{2} \text { at } \\
325 \mathrm{~nm}\end{array}$ & $\begin{array}{l}\mathrm{d}^{2} \mathrm{~F} / \mathrm{dx}^{2} \text { at } \\
348 \mathrm{~nm}\end{array}$ & $\begin{array}{l}d^{2} F / d x^{2} \text { at } \\
364 \mathrm{~nm}\end{array}$ & $\begin{array}{l}\text { Gross fluorescence } \\
\left(\text { ref. }^{26}\right)\end{array}$ \\
\hline \multicolumn{6}{|l|}{ M-TTR } \\
\hline$\Delta G_{U-F}^{H 20}\left(\mathrm{~kJ} \mathrm{~mol}^{-1}\right)$ & $20.7 \pm 3.5$ & $21.3 \pm 4.0$ & $20.0 \pm 8.0$ & $19.7 \pm 4.5$ & $20.4 \pm 1.5$ \\
\hline $\mathrm{m}\left(\mathrm{kJ} \mathrm{mol}{ }^{-1} \mathrm{M}^{-1}\right)$ & $7.8 \pm 1.3$ & $7.1 \pm 1.3$ & $7.8 \pm 2.9$ & $7.7 \pm 1.6$ & $6.9 \pm 0.5$ \\
\hline $\mathrm{C}_{\mathrm{m}}(\mathrm{M})$ & $2.8 \pm 0.2$ & $3.0 \pm 0.3$ & $2.6 \pm 0.3$ & $2.5 \pm 0.4$ & $3.0 \pm 0.1$ \\
\hline \multicolumn{6}{|l|}{ W79F M-TTR } \\
\hline Parameter & $\begin{array}{l}\text { Gross fluorescence } \\
\text { at } 330 \mathrm{~nm}\end{array}$ & $\begin{array}{l}d^{2} F / d x^{2} \text { at } \\
324 \mathrm{~nm}\end{array}$ & $\begin{array}{l}\mathrm{d}^{2} \mathrm{~F} / \mathrm{dx}^{2} \text { at } \\
346 \mathrm{~nm}\end{array}$ & $\begin{array}{l}d^{2} F / d x^{2} \text { at } \\
367 \mathrm{~nm}\end{array}$ & \begin{tabular}{|l} 
Gross fluorescence \\
$\left(\right.$ ref. $\left.^{26}\right)$
\end{tabular} \\
\hline$\Delta G_{U-F}^{H 20}\left(\mathrm{~kJ} \mathrm{~mol}^{-1}\right)$ & $12.9 \pm 1.3$ & $12.9 \pm 2.8$ & n.d & $21 \pm 14$ & $13.0 \pm 1.4$ \\
\hline $\mathrm{m}\left(\mathrm{kJ} \mathrm{mol} \mathrm{m}^{-1} \mathrm{M}^{-1}\right)$ & $4.2 \pm 0.4$ & $4.4 \pm 0.08$ & n.d & $6.6 \pm 4.3$ & $4.3 \pm 0.4$ \\
\hline $\mathrm{C}_{\mathrm{m}}(\mathrm{M})$ & $3.1 \pm 0.2$ & $3.0 \pm 0.1$ & n.d & $3.2 \pm 0.2$ & $3.0 \pm 0.1$ \\
\hline
\end{tabular}

Table 1. Thermodynamic parameters of M-TTR and W79F M-TTR urea-induced unfolding measured with conventional fluorescence and second derivative spectra ${ }^{\mathrm{a}}$. All data are derived from the data shown in Figs 5 and 6, except those of the last column, previously determined ${ }^{26}$.

occurs, as the $\mathrm{pH}$ decreases further down to 1.5 (Fig. 7A,B), indicating a change of the chemical environment around $\mathrm{Trp} 41$ at these extreme $\mathrm{pH}$ values.

The second derivative spectra are characterised by negative peaks at 325, 348 and $369 \mathrm{~nm}$ (Fig. 7C), whose values increase linearly (or become more negative) as the $\mathrm{pH}$ decreases from 10.0 to 3.4 (Fig. 7D), confirming the results obtained with the gross spectra. However, the peak at $325 \mathrm{~nm}$ decreases in intensity, the peak at $369 \mathrm{~nm}$ increases and that at $348 \mathrm{~nm}$ remains apparently constant, as the $\mathrm{pH}$ decreases further from 3.4 to 1.5 . This indicates that the distribution of the three conformers of Trp41 observed at mildly alkaline, neutral or mildly acidic $\mathrm{pH}$ values changes upon unfolding at low $\mathrm{pH}$. Interestingly, the change observed in the urea-unfolded state is more pronounced relative to the acid-unfolded state (Compare Figs 5D and 7D), indicating a lower degree of conformational change in the latter case. It is remarkable to observe, however, that the distribution of the three conformers of Trp41 does not change within the window of $\mathrm{pH}$ values where the amyloidogenic state is populated ( $\mathrm{pH}$ 3.9-5.0). Nor does the chemical environment around the residue appear to be modified.

We also characterized the amyloidogenic conformation of M-TTR at $\mathrm{pH} 4.45$ at various ionic strength ranging from 30 to $120 \mathrm{mM}$, as the increase of ionic strength is known to increase the rate of M-TTR aggregation ${ }^{26}$. We acquired the fluorescence spectra of M-TTR (excitation $280 \mathrm{~nm}$ ) in 4 different samples having the same pH value of 4.45 but different ionic strength values due to progressive additions of a $2 \mathrm{M} \mathrm{KCl}$ solution up to $30,60,90,120 \mathrm{mM}$ ionic strength, after incubation at $37^{\circ} \mathrm{C}$ for $30 \mathrm{~min}$. The fluorescence emission intensity appears to decrease linearly with increasing ionic strength from $30 \mathrm{mM}$ to $120 \mathrm{mM}$ (Fig. 8A,B), suggesting a typical solvent effect, probably due to the fluorescence quenching by the chloride ion. The second derivative spectra are characterized by negative peaks at 325,348 and $369 \mathrm{~nm}$, which decreased in intensity (became less negative) to similar extents as the ionic strength increases, indicating that the observed distribution of Trp41 does not change (Fig. 8C,D). This finding suggests that the effect of the ionic strength on the aggregation rate of the protein at mildly acidic $\mathrm{pH}$ is due to changes in dynamics or conformation of protein regions other than Trp41 or to solvent effects, most likely arising from the ability of the salts to shield the electrostatic repulsions between individual M-TTR molecules.

\section{Discussion}

The Trp41 residue of M-TTR is the only residue contributing significantly to the intrinsic fluorescence of M-TTR in a folded state, as Trp79 is quenched and manifests its fluorescence only in denatured states, in agreement with an unrelated analysis carried out on WT-TTR ${ }^{19}$. The fluorescence spectrum of Trp41 can be dissected in three main peaks that become apparent only in the second derivative spectra and correspond to three different conformers or rotamers of its side chain. Indeed, the three peaks have similar values of FRET efficiency with an acceptor located at Cys10, ruling out that one or more of such peaks arise from artifacts or other fluorophores present on the protein or in the sample as impurities.

The different wavelengths of maximum fluorescence of the three Trp41 conformers suggest that they have different degrees of hydrophobic contacts, hydrogen bonding and solvent exposure ${ }^{32,45}$. In particular, the first peak at ca. 322-325 $\mathrm{nm}$ can be assigned to class S tryptophan residues or, more likely, class I according to the classification previously proposed ${ }^{32,45}$ : Class I residues are buried tryptophan residues with substantial hydrogen bonding (exciplexes with 1:2 stoichiometry), high relative polarity, low packing density and great microenvironment flexibility. The second peak at 342-344 nm can be assigned to class II or III: tryptophan residues with established contacts with structured (class II) or highly mobile (class III) water molecules and having total solvent accessibility and free dynamics. The third peak at 364-366 nm can only be a class III tryptophan. The results obtained by quenching the intrinsic fluorescence of M-TTR with progressive additions of acrylamide confirm the hypothesis that the $322-325 \mathrm{~nm}$ peak arises from a fairly buried conformer of Trp41, as the quenching is lower relative to the other two peaks, which appear by contrast to be fully solvent exposed and thus more susceptible to acrylamide quenching.

The distribution of the relative fractions of the three conformers change with urea-induced unfolding of M-TTR. The 322-325 nm fluorescence peak loses most of its intensity, whereas the other two peaks at 342-344 and 364$366 \mathrm{~nm}$ gain intensity as they are also enriched by the contribution from Trp79 that is no longer quenched and solvent exposed in the urea-denatured state. The urea-induced unfolding of the W79F mutant is more informative in this regard, as the fluorescence spectra of both the folded and unfolded states arise solely from Trp41. In this case we can observe a decrease and increase of the relative intensities of the $322-325 \mathrm{~nm}$ and $364-366 \mathrm{~nm}$ peaks, whereas the 

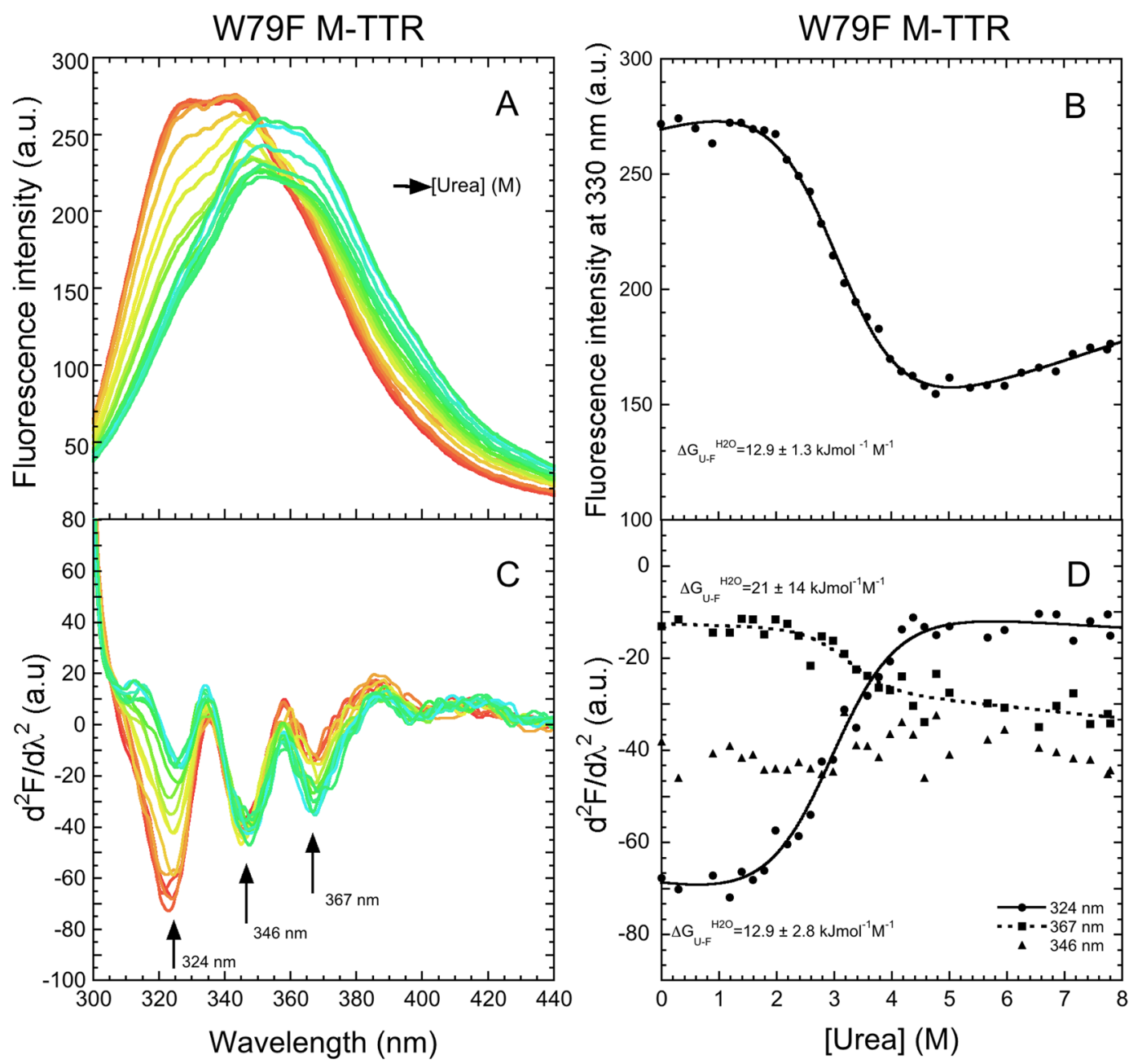

Figure 6. Equilibrium urea unfolding of W79F M-TTR. (A) Fluorescence spectra at $3 \mu \mathrm{M}$ protein concentration and urea concentration ranging from 0 to $7.8 \mathrm{M}$ in $20 \mathrm{mM}$ phosphate buffer at $\mathrm{pH} 7.4,25^{\circ} \mathrm{C}$ (excitation $290 \mathrm{~nm}$, slits 5 and $10 \mathrm{~nm}$ for ex and em, respectively). (B) Urea denaturation curve using W79F M-TTR fluorescence at $330 \mathrm{~nm}$. The solid line through the data represents the best fit to a two-state model (Santoro and Bolen, 1988). The obtained $\Delta G_{U-F}^{H 20}$ value is shown. (C) Corresponding second derivative spectra with arrows indicating the three major peaks. (D) Values of second derivative at 324, 346 and $367 \mathrm{~nm}$ versus urea concentration, plotted to obtain urea denaturation curves. The solid lines through the data represent the best fit to a two-state model (Santoro and Bolen, 1988). The obtained $\Delta G_{U-F}^{H 20}$ values are shown.

342-344 nm peak remains constant. Overall, therefore, we have a conversion of some of the Trp41 moieties adopting the first conformation to the second and third conformation, and some of the Trp41 moieties adopting the second to the third. Interestingly, we also observed the maintenance of a residual intensity of the $322-325 \mathrm{~nm}$ peak in the urea-unfolded state, even at the highest urea concentrations tested here, well beyond the window of urea concentration where the main transition occurs. This indicates that a small fraction of the Trp41 residue maintains the most structured conformation adopted in the folded state and provides further evidence that residual native-like structure is retained, to a small but significant degree, in fully unfolded states of proteins ${ }^{46,47}$.

This scenario is similar following acidic-induced unfolding of M-TTR at $\mathrm{pH}$ extremes, with the first, second and third peaks decreasing, remaining constant and increasing in intensity, respectively. The unfolding is more modest in this case as the changes are all less marked relative to those observed in urea-induced unfolding of M-TTR (Compare Figs 5D and 7D). Again, the persistence of the 322-325 nm peak in the acidic-unfolded state indicates the presence of some degree of native-like residual structure in the Trp41 microenvironment.

The $\mathrm{pH}$ titration analysis, and the following ionic strength titration at the selected $\mathrm{pH}$ value of 4.45 , also allow to determine that at the $\mathrm{pH}$ values of 3.9-5.0 and various values of ionic strength, in which the amyloidogenic state of the protein is populated ${ }^{19,20,24,26}$, the distribution of the three conformers of $\operatorname{Trp} 41$ is maintained with respect to that observed at neutral $\mathrm{pH}$ values and low ionic strength, where the protein is folded and fully soluble. This indicates that the microenvironment around Trp41 is maintained in the transition of M-TTR from the folded state to the amyloidogenic state. This finding is in agreement with other previously obtained observations. First, FRET measurements showed that the distance between Trp 41 and Cys 10 is maintained in the same range of pH values following this conformational conversion ${ }^{26}$. Second, solution nuclear magnetic resonance (NMR) studies 

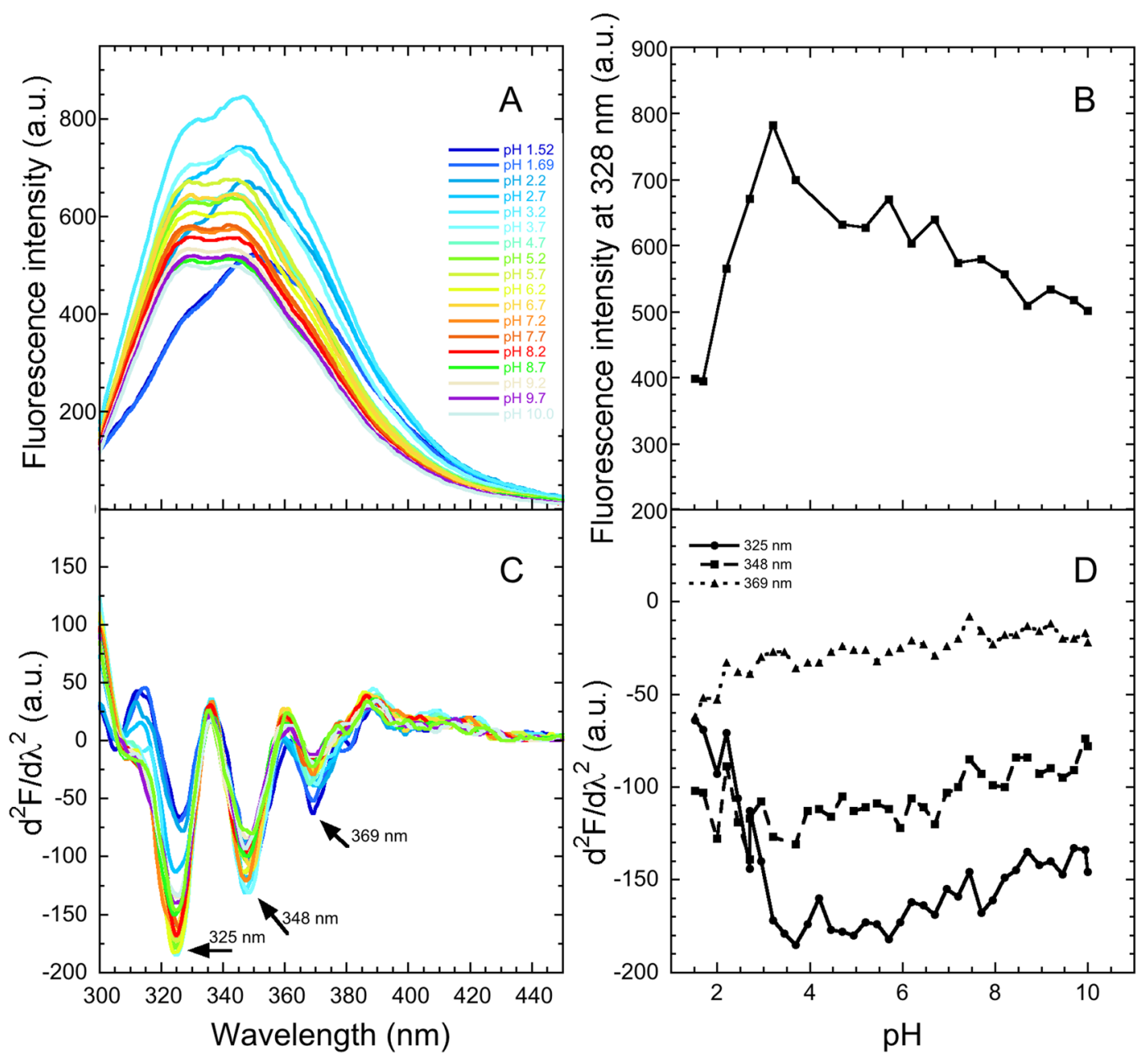

Figure 7. $\mathrm{pH}$ titration of M-TTR. (A) Fluorescence spectra (excitation $280 \mathrm{~nm}$, slits 5 and $7 \mathrm{~nm}$ for ex and em, respectively) of $3 \mu \mathrm{M} \mathrm{M}$-TTR in different buffers with the indicated $\mathrm{pH}$ values ranging from 1.52 to 10.0 , total ionic strength $30 \mathrm{mM}$, at $25^{\circ} \mathrm{C}$. (B) Plot of fluorescence intensity value at $335 \mathrm{~nm}$ versus $\mathrm{pH}$. (C) Corresponding second derivative spectra with arrows indicating the three major peaks. (D) Values of second derivative at 325 , 348 and $369 \mathrm{~nm}$ versus $\mathrm{pH}$.

revealed that the entire $\mathrm{CBEF} \beta$-sheet, including the Trp41-containing $\beta$-strand $\mathrm{C}$, maintains a fully native-like structure and the same dynamics following the transition of folded M-TTR and WT-TTR into the amyloidogenic state at moderately acidic $\mathrm{pH}$ values ${ }^{22,24}$. Indeed, a reconciling picture of the amyloidogenic state of TTR populated at moderately low $\mathrm{pH}$ that is in agreement with all data obtained so far is a largely native-like state with the D-E loop, the E-F $\alpha$-helix (as well as its interconnected residues from the A-B loop), and the whole DAGH $\beta$-sheet exhibiting significant dynamical behaviour against a substantially packed CBEF sheet.

It will be interesting to extend these studies to include other techniques, such as near-UV CD and solution-state NMR in different conditions, to see if they can also detect a distribution of conformations for Trp41, and possibly other residues, and also determine their precise structure and how the distribution changes with solution conditions and mutations. The two solution NMR and X-ray structures deposited in the protein data bank (PDB entries $2 \mathrm{NBO}$ and 1GKO, respectively) have shown two different conformations for Trp41, as the spatial superimposition of the two structures reveals that the planes of the indole groups form an angle of $\mathrm{ca} .90^{\circ}$ due to a different rotation of the $\mathrm{C}_{\beta}-\mathrm{C}_{\chi}$ covalent bond, revealing that a structural plasticity exists for this residue. However, it will be interesting to detect such a conformational distribution within the same sample of M-TTR and how it changes in various contexts.

\section{Conclusions}

In more generic terms, we have shown how the use of second derivative intrinsic fluorescence spectroscopy allows to determine the distribution of the various conformers of a given tryptophan residue in a given protein. It constitutes, therefore, a valuable probe to monitor the changes in conformation and dynamics of a protein of interest, such as those occurring following urea-induced unfolding, acidic-induced unfolding and the structural conversion into the amyloidogenic state for M-TTR. The various conformers can be followed individually during any given conformational conversion and the change of their distribution allows to determine not just the conformational change occurring for a give tryptophan residue and the change of its chemical microenvironment, but 

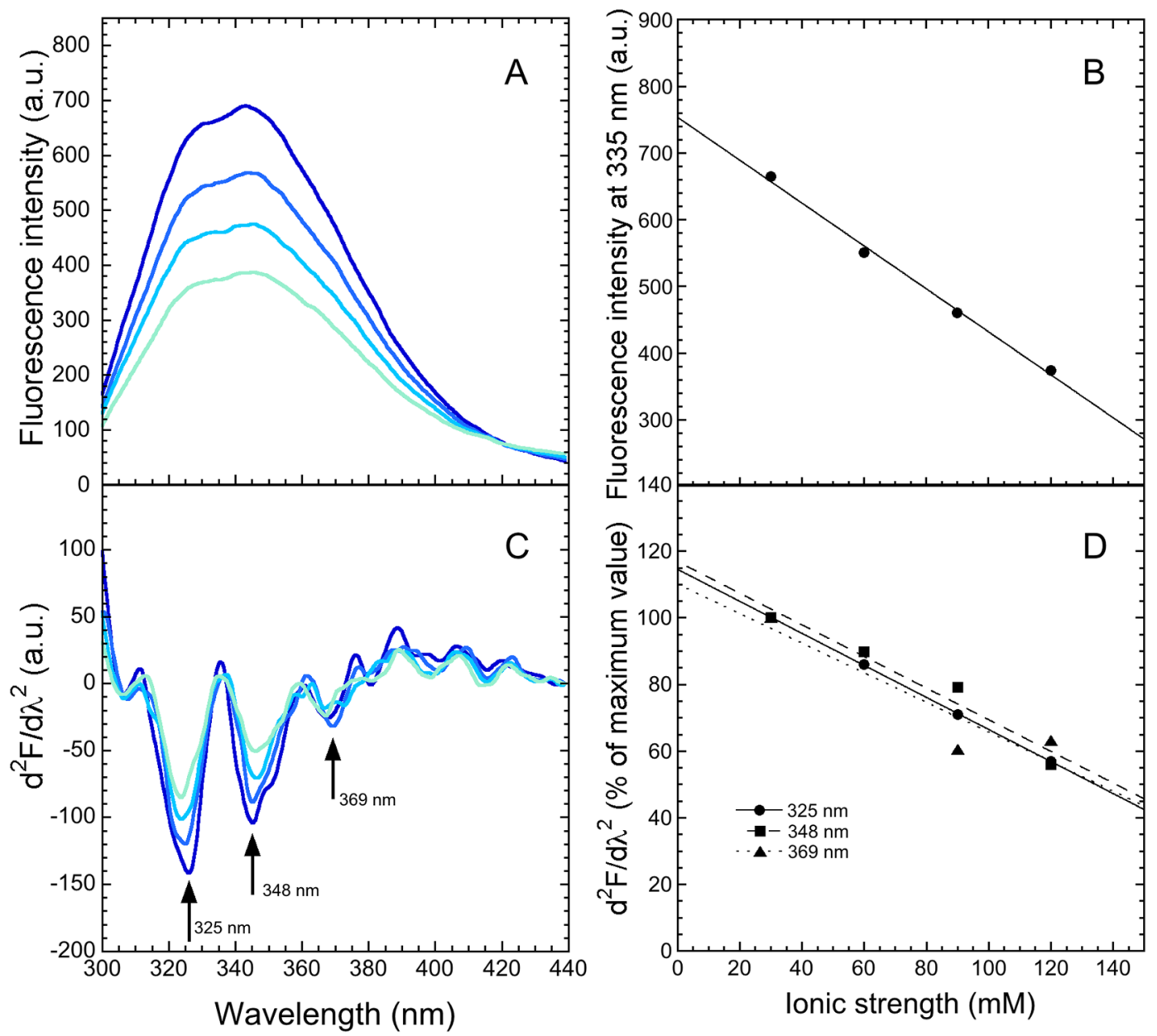

Figure 8. Gross and second derivative fluorescence spectra of M-TTR at low $\mathrm{pH}$ with various ionic strengths. (A) Fluorescence spectra of $125 \mu \mathrm{M}$ M-TTR in $10 \mathrm{mM}$ acetate buffer, $\mathrm{pH} 4.45,37^{\circ} \mathrm{C}$ at the indicated total ionic strength $(\mu$ ) ranging from $30-120 \mathrm{mM}$ (excitation $280 \mathrm{~nm}$, slits 7.5 and $8 \mathrm{~nm}$ for ex and em, respectively). (B) Plot of fluorescence intensity value at $335 \mathrm{~nm}$ versus ionic strength. (C) Corresponding second derivative spectra with arrows indicating the three major peaks. (D) Values of second derivative at 325, 348 and 369 nm versus ionic strength. The lines through the data represent the best fits to a linear function of the form $\mathrm{d}^{2} \mathrm{~F} / \mathrm{d} \lambda^{2}=100 \%+a \cdot \mu$.

also the change of the microenvironment dynamics around it and the extent to which native-like conformers are maintained in a given non-native state.

\section{Experimental Procedures}

Materials. Dimethyl sulfoxide (DMSO), glutathione (GSH), Tris, citrate, formate, acetate, MES, phosphate, borate, trifluoroacetic acid (TFA), acrylamide, urea, N-acetyl-L-tryptophanamide (NATA) and L-tryptophan were purchased from Sigma-Aldrich (St Louis, MO, USA). N-(7-Dimethylamino-4-methylcoumarin-3-yl) maleimide (DACM) was purchased from Thermo Fisher Scientific (Waltham, MA, USA).

Protein expression and purification. M-TTR and its W79F mutant were expressed and purified as formerly described ${ }^{3}$. They were then stored in $20 \mathrm{mM}$ phosphate buffer, $\mathrm{pH} 7.4,-20^{\circ} \mathrm{C}$. In all cases, purity of the collected proteins was found by SDS-PAGE to be $>95 \%$.

Protein labelling with DACM. Each protein variant was diluted to $0.2 \mathrm{mM}$ in $20 \mathrm{mM}$ phosphate buffer at $\mathrm{pH} 7.4,25^{\circ} \mathrm{C}$. DACM aliquots solubilised in DMSO (99.9\%) were added to a tenfold higher concentration of dye. The sample was covered with aluminium foil and incubated under shaking at $37^{\circ} \mathrm{C}$ for $1 \mathrm{~h}$. The reaction was stopped using $5 \mu \mathrm{l}$ of TFA. The free dye was eliminated by dialysis ( $3.0 \mathrm{kDa}$ molecular weight cut off), and then the sample was centrifuged. The concentration of DACM in labelled protein sample was estimated using $\varepsilon_{381}=27,000 \mathrm{M}^{-1} \mathrm{~cm}^{-1}$, whereas protein concentration was calculated with $\varepsilon_{280}=18,450 \mathrm{M}^{-1} \mathrm{~cm}^{-1}$ for labelled M-TTR and $\varepsilon_{280}=12,950 \mathrm{M}^{-1} \mathrm{~cm}^{-1}$ for labelled W79F M-TTR. The contribution of an equimolar concentration of DACM-GSH at $280 \mathrm{~nm}$ was subtracted to calculate the difference. A normalization of absorbance spectra of DACM-GSH and DACM-M-TTR (or its mutant) was carried out. 
Fluorescence spectroscopy. A PerkinElmer LS 55 spectrofluorimeter (Waltham, MA, USA), provided with a thermostated cell holder attached to a HAAKE F8 water bath (Karlsruhe, Germany) and a $2 \times 10 \mathrm{~mm}$ or $4 \times 10 \mathrm{~mm}$ quartz cuvette were used for recording fluorescence spectra $(290 \mathrm{~nm}$ excitation except $\mathrm{pH}$ titration and ionic strength analysis at $280 \mathrm{~nm}$ ). For each sample three fluorescence spectra were acquired, blank subtracted and averaged. Intrinsic fluorescence emission spectra were transformed in their second derivative, which consists of the second order derivative of fluorescence $(F)$ with respect to wavelength $\lambda\left(\mathrm{d}^{2} F / \mathrm{d} \lambda^{2}\right)$. The second derivative spectra were calculated using the dedicated software for data analysis of the PerkinElmer LS 55 spectrofluorimeter and data windows of 30 points $(15 \mathrm{~nm})$.

M-TTR, W79F M-TTR, NATA, L-tryptophan fluorescence spectra. $\quad 0.5 \mathrm{ml}$ of $3 \mu \mathrm{M} \mathrm{M}$-TTR, or W79F $\mathrm{M}$-TTR, or L-tryptophan or NATA in $20 \mathrm{mM}$ phosphate buffer $\mathrm{pH} 7.4$ were prepared to acquire fluorescence spectra from 300 to $460 \mathrm{~nm}$ at $25^{\circ} \mathrm{C}$ in a $2 \times 10 \mathrm{~mm}$ quartz cuvette ( $290 \mathrm{~nm}$ excitation). NATA is an N-terminal and C-terminal blocked analogue of L-tryptophan.

FRET. For FRET measurements, unlabelled or DACM-labelled M-TTR (or its W79F mutant) were diluted to a concentration of $3 \mu \mathrm{M}$, in $20 \mathrm{mM}$ phosphate buffer, $\mathrm{pH} 7.4,25^{\circ} \mathrm{C}$ and mixed to achieve different percentages of labelled and unlabelled M-TTR (or W79F M-TTR) from 0 to 100\%. Fluorescence spectra were recorded from 290 to $450 \mathrm{~nm}(290 \mathrm{~nm}$ excitation) with a $10 \times 2$ quartz cuvette and the fluorimeter described above. The fluorescence emission spectrum of the unlabelled sample showed a peak at $330-350 \mathrm{~nm}$ and the labelled sample $(100 \%$ DACM-M-TTR) a low intensity peak at 330-350 $\mathrm{nm}$ and an intense peak at $465 \mathrm{~nm}$ due to the energy transfer from excited tryptophan residues to the DACM group. Values of second derivative were plotted as a function of DACM-labelling percentage for the three peaks of M-TTR and W79F M-TTR in the window of 320-370 nm, after normalisation to attribute $100 \%$ to the second derivative values determined with $0 \%$ labelling.

Fluorescence quenching by acrylamide. M-TTR variants were diluted to $2.2 \mu \mathrm{M}$ (M-TTR) or $3.5 \mu \mathrm{M}$ (W79F mutant) in $20 \mathrm{mM}$ phosphate buffer, $\mathrm{pH} 7.4$ to obtain samples of exactly $1000 \mu \mathrm{l}$ and incubated at $25^{\circ} \mathrm{C}$. $5 \mu \mathrm{L}$ aliquots of $2.5 \mathrm{M}$ acrylamide solution (at $25^{\circ} \mathrm{C}$ ) were progressively added to $1 \mathrm{ml}$ of protein sample up to $50 \mu \mathrm{L}$. Between the various additions, fluorescence spectra from 300 to $420 \mathrm{~nm}$ ( $290 \mathrm{~nm}$ excitation) were recorded under constant stirring using the fluorimeter described above and a quartz cuvette $4 \times 10 \mathrm{~mm}$. The plot of total tryptophan fluorescence versus acrylamide concentration was analysed using the following linear Stern-Volmer relationship:

$$
\frac{F_{0}}{F}=\left(1+K_{S V} *[\text { Acrylamide }]\right)
$$

where $K_{\mathrm{SV}}$ is the Stern-Volmer constant and is proportional to the degree of tryptophan exposure to the solvent, $F_{0}$ is the fluorescence spectrum area without acrylamide and $F$ is that with acrylamide; all spectra are corrected by

$$
F=F_{0} / \mathrm{A} ; \mathrm{A}=1000 / 1000+V_{\text {acrylamide }}
$$

where $V_{\text {acrylamide }}$ is the acrylamide volume.

The same analysis was repeated using the negative peak values of the second derivative spectra at 323,343 and $362 \mathrm{~nm}$ of M-TTR and only at $323 \mathrm{~nm}$ of its W79F mutant, as the subsequent peaks ( 347 and $355 \mathrm{~nm}$ ) where not considered for the noisiness of the spectra.

Equilibrium urea unfolding. A number of samples of $60 \mu \mathrm{M}$ M-TTR or $3 \mu \mathrm{M}$ W79F M-TTR in $20 \mathrm{mM}$ phosphate buffer, $\mathrm{pH} 7.4$ with varying urea concentrations $(0-7.8 \mathrm{M})$, were prepared and incubated at $25^{\circ} \mathrm{C}$ for $1 \mathrm{~h}$ in a water bath. Fluorescence spectra were recorded at $25^{\circ} \mathrm{C}$ from 300 to $500 \mathrm{~nm}(290 \mathrm{~nm}$ excitation) with a $4 \times 10 \mathrm{~mm}$ quartz cuvette and the fluorimeter described above. The resulting plots of fluorescence intensity at 362 and $330 \mathrm{~nm}$ againts the concentration of urea were analysed with a two-state folding model ${ }^{23,43,44}$ for M-TTR and its W79F mutant, respectively, in order to obtain quantitative measurements of the free energy change upon unfolding in the absence of denaturant $\left(\Delta G_{U-F}^{H 20}\right)$, the concentration of middle unfolding $\left(\mathrm{C}_{m}\right)$ and the dependence of the free energy change upon unfolding on urea concentration ( $m$ value). The same analysis was repeated using the negative peak values of the second derivative spectra at 325, 348 and $364 \mathrm{~nm}$ for M-TTR and at 324 and $367 \mathrm{~nm}$ for its W79F mutant.

pH titration. 36 samples of $3 \mu \mathrm{M}$ M-TTR in 36 different buffers ranging from $\mathrm{pH} 1.52$ to 10.0 and constant ionic strength of $30 \mathrm{mM}$ were prepared and incubated in water bath at $25^{\circ} \mathrm{C}$ for $30 \mathrm{~min}$. The first three buffers ranging from $\mathrm{pH} 1.52$ to 2.0 were prepared using $\mathrm{HCl}$ at $10,20,30 \mathrm{mM}$. In order to cover the remaining $\mathrm{pH}$ range 2.2-10.0, the buffers prepared were citrate $(\mathrm{pH} 2.2-2.9)$, formate $(\mathrm{pH} 2.9-3.9)$, acetate $(\mathrm{pH} 3.9-5.6)$, MES ( $\mathrm{pH}$ 5.6-6.5), phosphate ( $\mathrm{pH} 6.5-7.5)$, tris $(\mathrm{pH} 7.5-8.8)$ and borate $(\mathrm{pH} 8.8-10.0)$, all at $10 \mathrm{mM}$ concentration and using $\mathrm{NaCl}$ to bring the total ionic strength to $30 \mathrm{mM}$. Fluorescence spectra were recorded at $25^{\circ} \mathrm{C}$ from 300 to $450 \mathrm{~nm}$ (excitation $280 \mathrm{~nm}$ ) using a $2 \times 10 \mathrm{~mm}$ quartz cuvette and the fluorimeter described above. A plot of fluorescence intensity at $335 \mathrm{~nm}$ versus $\mathrm{pH}$ was obtained. Plots of negative peaks at 325,348 and $369 \mathrm{~nm}$ of the second derivative spectra versus $\mathrm{pH}$ were also produced.

Ionic strength analyses. 4 samples of M-TTR at $125 \mu \mathrm{M}$ in $10 \mathrm{mM}$ acetate buffer, $\mathrm{pH} 4.45$ that differed in ionic strength due to progressive additions of small volumes of a $2 \mathrm{M} \mathrm{KCl}$ solution up to $30,60,90$ and $120 \mathrm{mM}$, were prepared and incubated at $37^{\circ} \mathrm{C}$ for $30 \mathrm{~min}$ in a water bath. Between the various additions, fluorescence spectra from 300 to $440 \mathrm{~nm}$ (excitation $280 \mathrm{~nm}$ ) were recorded using a $2 \times 10 \mathrm{~mm}$ quartz cuvette. Corresponding second derivative spectra show negative peaks at 325,348 and $369 \mathrm{~nm}$. 


\section{Data Availability}

The datasets generated during and/or analysed during the current study are available from the corresponding author on reasonable request.

\section{References}

1. Vieira, M. \& Saraiva, M. J. Transthyretin: a multifaceted protein. Biomol. Concepts 5, 45-54 (2014).

2. Alshehri, B., D’Souza, D. G., Lee, J. Y., Petratos, S. \& Richardson, S. J. The diversity of mechanisms influenced by transthyretin in neurobiology:development, disease and endocrine disruption. J. Neuroendocrinol. 27, 303-323 (2015).

3. Reixach, N. et al. Human-murine transthyretin heterotetramers are kinetically stable and non-amyloidogenic. A lesson in the generation of transgenic models of diseases involving oligomeric proteins. J. Biol. Chem. 283, 2098-2107 (2008).

4. Buxbaum, J. N. \& Reixach, N. Transthyretin: the servant of many masters. Cell Mol Life Sci. 66, 3095-3101 (2009).

5. Sekijima, Y. et al. The biological and chemical basis for tissue-selective amyloid disease. Cell. 121, 73-85 (2005).

6. Chiti, F. \& Dobson, C. M. Protein Misfolding, Amyloid Formation, and Human Disease: A Summary of Progress Over the Last Decade. Annu Rev Biochem. 86, 27-68 (2017).

7. Sekijima, Y. Transthyretin (ATTR) amyloidosis: clinical spectrum, molecular pathogenesis and disease-modifying treatments. J Neurol Neurosurg Psychiatry. 86, 1036-1043 (2015).

8. Sipe, J. D. et al. Amyloid fibril proteins and amyloidosis: chemical identification and clinical classification International Society of Amyloidosis 2016 Nomenclature Guidelines. Amyloid. 23, 209-213 (2016).

9. Lie, J. T. \& Hammond, P. I. Pathology of the senescent heart: anatomic observations on 237 autopsy studies of patients 90 to 105 years old. Mayo Clin Proc. 63, 552-564 (1988).

10. Tanskanen, M. et al. Senile systemic amyloidosis affects $25 \%$ of the very aged and associates with genetic variation in alpha2macroglobulin and tau: a population-based autopsy study. Ann Med. 40, 232-239 (2008).

11. Garzuly, F., Vidal, R., Wisniewski, T., Brittig, F. \& Budka, H. Familial meningocerebrovascular amyloidosis, Hungarian type, with mutant transthyretin (TTR Asp18Gly). Neurology. 47, 1562-1567 (1996).

12. Connors, L. H., Lim, A., Prokaeva, T., Roskens, V. A. \& Costello, C. E. Tabulation of human transthyretin (TTR) variants. Amyloid. 10, 160-184 (2003).

13. Cornwell, G. G. III., Sletten, K., Johansson, B. \& Westermark, P. Evidence that the amyloid fibril protein in senile systemic amyloidosis is derived from normal prealbumin. Biochem Biophys Res Commun. 154, 648-653 (1988).

14. Saraiva, M. J., Costa, P. P. \& Goodman, D. S. Transthyretin (prealbumin) in familial amyloidotic polyneuropathy: genetic and functional aspects. Adv Neurol. 48, 189-200 (1988).

15. Westermark, P., Sletten, K., Johansson, B. \& Cornwell, G. G. III. Fibril in senile systemic amyloidosis is derived from normal transthyretin. Proc Natl Acad Sci USA 87, 2843-2845 (1990).

16. Mccutchen, S. L., Colon, W. \& Kelly, J. W. Transthyretin Mutation Leu-55-Pro Significantly Alters Tetramer Stability and Increases Amyloidogenicity. Biochemistry. 32, 12119-12127 (1993).

17. Steinrauf, L. K., Hamilton, J. A., Braden, B. C., Murrell, J. R. \& Benson, M. D. X-ray crystal structure of the Ala-109->Thr variant of human transthyretin which produces euthyroid hyperthyroxinemia. J Biol Chem. 268, 2425-2430 (1993).

18. Peterson, S. A. et al. Inhibiting transthyretin conformational changes that lead to amyloid fibril formation. Proc Natl Acad Sci USA 95, 12956-12960 (1998).

19. Lai, Z., Colon, W. \& Kelly, J. W. The acid-mediated denaturation pathway of transthyretin yields a conformational intermediate that can self-assemble into amyloid. Biochemistry. 35, 6470-6482 (1996).

20. Kelly, J. W. et al. Transthyretin quaternary and tertiary structural changes facilitate misassembly into amyloid. Adv Protein Chem. 50, 161-181 (1997).

21. Liu, K. et al. Deuterium-proton exchange on the native wild-type transthyretin tetramer identifies the stable core of the individual subunits and indicates mobility at the subunit interface. J Mol Biol. 303, 555-565 (2000).

22. Lim, K. H. et al. Structural Changes Associated with Transthyretin Misfolding and Amyloid Formation Revealed by Solution and Solid-State NMR. Biochemistry. 55, 1941-1944 (2016).

23. Jiang, X. et al. An engineered transthyretin monomer that is nonamyloidogenic, unless it is partially denatured. Biochemistry. 40, $11442-11452(2001)$.

24. Lim, K. H., Dyson, H. J., Kelly, J. W. \& Wright, P. E. Localized Structural Fluctuations Promote Amyloidogenic Conformations in Transthyretin. Journal of Molecular Biology. 425, 977-988 (2013).

25. Oroz, J., Kim, J. H., Chang, B. J. \& Zweckstetter, M. Mechanistic basis for the recognition of a misfolded protein by the molecular chaperone Hsp90. Nat Struct Mol Biol. 24, 407-413 (2017).

26. Ghadami, S. A. et al. FRET studies of various conformational states adopted by transthyretin. Cell Mol Life Sci. 74, 3577-3598 (2017).

27. Bateman, D. A., Tycko, R. \& Wickner, R. B. Experimentally derived structural constraints for amyloid fibrils of wild-type transthyretin. Biophys J. 101, 2485-2492 (2011).

28. Lim, K. H. et al. Pathogenic Mutations Induce Partial Structural Changes in the Native $\beta$-Sheet Structure of Transthyretin and Accelerate Aggregation. Biochemistry. 56, 4808-4818 (2017).

29. Ferrão-Gonzales, A. D., Souto, S. O., Silva, J. L. \& Foguel, D. The preaggregated state of an amyloidogenic protein: hydrostatic pressure converts native transthyretin into the amyloidogenic state. Proc Natl Acad Sci USA 97, 6445-6450 (2000).

30. Conti, S. et al. A complex equilibrium among partially unfolded conformations in monomeric transthyretin. Biochemistry. 53, 4381-4392 (2014).

31. Ramsay, G. \& Eftink, M. R. A multidimensional spectrophotometer for monitoring thermal unfolding transitions of macromolecules. Biophys J. 66, 516-523 (1994).

32. Reshetnyak, Y. K., Koshevnik, Y. \& Burstein, E. A. Decomposition of protein tryptophan fluorescence spectra into log-normal components. III. Correlation between fluorescence and microenvironment parameters of individual tryptophan residues. Biophys J. 81, 1735-1758 (2001).

33. Royer, C. A. Probing protein folding and conformational transitions with fluorescence. Chem Rev. 106, 1769-1784 (2006).

34. Lakowicz, J. R. Principles of fluorescence spectroscopy. 16, 529-575. 3rd edn. Springer, New York (2006).

35. Mozo-Villarías, A. Second derivative fluorescence spectroscopy of tryptophan in proteins. J Biochem Biophys Methods. 50, 163-178 (2002).

36. Nayar, S., Brahma, A., Mukherjee, C. \& Bhattacharyya, D. Second derivative fluorescence spectra of indole compounds. J. Biochem. 131, 427-435 (2002).

37. Kumar, V., Sharma, V. K. \& Kalonia, D. S. Second derivative tryptophan fluorescence spectroscopy as a tool to characterize partially unfolded intermediates of proteins. Int J Pharm. 294, 193-199 (2005).

38. Sarzehi, S. \& Chamani, J. Investigation on the interaction between tamoxifen and human holo-transferrin: determination of the binding mechanism by fluorescence quenching, resonance light scattering and circular dichroism methods. Int J Biol Macromol. 47, 558-569 (2010).

39. Abbas, S. A., Gaspar, G., Sharma, V. K., Patapoff, T. W. \& Kalonia, D. S. Application of second-derivative fluorescence spectroscopy to monitor subtle changes in a monoclonal antibody structure. J Pharm Sci. 102, 52-61 (2013). 
40. Reynolds, D. M. Rapid and direct determination of tryptophan in water using synchronous fluorescence spectroscopy. Water Res. 37, 3055-3060 (2003).

41. Clegg, R. M. Fluorescence resonance energy transfer. Curr Opin Biotechnol. 6, 103-110 (1995).

42. Stern, O. \& Volmer, M. Uber die Abklingungszeit der Fluoreszenz. Physikalische Zeitschrift. 20, 183-188 (1919).

43. Santoro, M. M. \& Bolen, D. W. Unfolding free energy changes determined by the linear extrapolation method.1 Unfolding of phenilmethanesulfonyl alpha-chimotrypsin using different denaturants. Biochemistry 27, 8063-8 (1988).

44. Taddei, N. et al. Stabilisation of alpha-helices by site-directed mutagenesis reveals the importance of secondary structure in the transition state for acylphosphatase folding. J. Mol. Biol. 300, 633-47 (2000).

45. Hixon, J. \& Reshetnyak, Y. K. Algorithm for the analysis of tryptophan fluorescence spectra and their correlation with protein structural parameters. Algorithms. 2, 1155-1176 (2009).

46. Shortle, D. \& Ackerman, M. S. Persistence of native-like topology in a denatured protein in 8 Murea. Science. 293, 487-489 (2001).

47. Ackerman, M. S. \& Shortle, D. Robustness of the long-range structure in denatured of staphylococcal nuclease to changes in amino acid sequence. Biochemistry. 41, 13791-13797 (2002).

\section{Acknowledgements}

We thank the Iranian Ministry of Science Research and Technology for providing the studentship for S.A.G. and the University of Florence for Fondi di Ateneo (F.C. and F.B).

\section{Author Contributions}

D.J. recorded the fluorescence spectra in Figures 1, 3, 4 and 5; S.A.G recorded the fluorescence spectra in Figures 2 and 6; F.B. recorded the fluorescence spectra in Figures 7 and 8. D.J. and F.C. performed the second derivative analysis off all spectra. D.J. edited all the figures. F.C. revised the whole work and wrote the manuscript. All authors discussed the results and contributed to the final manuscript.

\section{Additional Information}

Competing Interests: The authors declare no competing interests.

Publisher's note: Springer Nature remains neutral with regard to jurisdictional claims in published maps and institutional affiliations.

(c) (i) Open Access This article is licensed under a Creative Commons Attribution 4.0 International License, which permits use, sharing, adaptation, distribution and reproduction in any medium or format, as long as you give appropriate credit to the original author(s) and the source, provide a link to the Creative Commons license, and indicate if changes were made. The images or other third party material in this article are included in the article's Creative Commons license, unless indicated otherwise in a credit line to the material. If material is not included in the article's Creative Commons license and your intended use is not permitted by statutory regulation or exceeds the permitted use, you will need to obtain permission directly from the copyright holder. To view a copy of this license, visit http://creativecommons.org/licenses/by/4.0/.

(C) The Author(s) 2019 